\title{
Viability Selection of Bovine Oocyte Using Annexin-V Assay
}

\author{
Khairul Osman ${ }^{1}$, Nurhaslina Hassan ${ }^{2}$, Siti Fatimah Ibrahim ${ }^{3}$, Chew Fang Nang ${ }^{3} \&$ Zawawi Ismail $^{4}$ \\ ${ }^{1}$ Sperm Science Group, Centre of Diagnostic Science \& Applied Health, Faculty of Health Science, National \\ University of Malaysia (UKM-KL), Malaysia \\ ${ }^{2}$ Centre of Studies for Preclinical Science, Faculty of Dentistry, Universiti Teknologi MARA (UiTM), Malaysia \\ ${ }^{3}$ Department of Physiology, National University of Malaysia Medical Centre (PPUKM), Malaysia \\ ${ }^{4}$ Pusat Ternakan Tersat, Department of Veterinary Service, Malaysia \\ Correspondence: Khairul Osman, Sperm Science Group, Centre of Diagnostic Science \& Applied Health, Faculty \\ of Health Science, National University of Malaysia (UKM-KL), Malaysia. E-mail: khairos@yahoo.com
}

Received: March 20, 2013 Accepted: April 21, 2013 Online Published: May 15, 2013

doi:10.5539/jas.v5n6p141 URL: http://dx.doi.org/10.5539/jas.v5n6p141

\begin{abstract}
Morphological characteristic is the primary reference for selecting viable cumulus-oocyte-complex (COCs). Annexin- $\mathrm{V}$ assay has been suggested for isolating these viable cells based on apoptosis status. This study compared fertilization rate between Annexin-V selected COCs with morphologically healthy selected COCs. Minimal binding time between Annexin- $\mathrm{V}$ and the COCs was determined to ensure slight disruption. Before observation with florescent microscope, eighty-two cattle's COCs were incubated with the Annexin-V assay for 5 $\min , 15 \mathrm{~min}$ and 24 hours. Further, 157 COCs were separated into 2 groups; positively $(\mathrm{n}=76)$ and negatively $(\mathrm{n}=81)$ tagged with annexin-V-FITC and PI fluorescent signals. Once separated, control comprised of non-stained $\mathrm{COC}(\mathrm{n}=68)$ and the two afore mentioned groups were matured, fertilized and cultured (IVM-IVF-IVC). After 72 hpi, cleavage rate was determined. Results shows the binding between annexin-V assay and the nonviable COC had occurred as early as 5 min with positively and negatively tagged COCs were $44(53.7 \%)$ and 38 (46.3\%) respectively. The fertilization rate of control group (66\%), negatively tagged $(79 \%)$ and positively $(50 \%)$ tagged COCs was significantly different $\left(\chi^{2}(2)=14.60, p<0.05\right)$ between the groups. In conclusion, oocyte selection using annexin-V-FITC had significant differences in cleavage rate compared with oocytes assumptive as morphologically healthy. Based on COCs Annexin- $\mathrm{V}$ assay, COC that are assumed as morphologically healthy is a mixture of viable and nonviable oocytes.
\end{abstract}

Keywords: annexin V-FITC, propidium iodide, apoptotic cumulus-oocyte complex, cleavage rate, In vitro fertilization (IVF)

\section{Introduction}

Viable oocyte selection prior to maturation process is an important step in achieving high successful in vitro fertilization rate (Camargo et al., 2006). To date, this selection of viable oocytes is solely based on morphological assessment (Plourde et al., 2012). The selection procedure which is consisted of assessment on follicle size, morphology of cumulus cells and homogeneity of the cytoplasm has been reported to cause biased (Blondin, Bousquet, Twagiramungu, Barnes, \& Sirard, 2002) and false interpretation. COCs that morphologically identified as early signs of atresia in contrast had shown good nuclear maturation and development potential than those considered to be morphologically viable (Bilodeau-Goeseels, 2001; De Wit, Wurth, \& Kruip, 2000). In addition, this assessment also takes longer time to assess especially when it involves high number of sample to be assessed in one particular day. Any further delay in placing the COC into the nutrient media for the maturation process will result in failure of fertilization.

A scientific approach is required such as annexin $\mathrm{V}$ assay which postulated to be an objective evidence in assessing oocyte quality that could offer less biasness and also shorten assessment time. The ability of annexin $\mathrm{V}$ fluoroscein isothiocyanate (FITC) to bind to expose phosphotidyl serine (PS) as an early indicator of apoptosis process is well studied (van Engeland, Nieland, Ramaekers, Schutte, \& Reutelingsperger, 1998). Even though there were several studies conducted in assessing the apoptotic oocyte using annexin v FITC (Anguita, Vandaele, Mateusen, Maes, \& Van Soom, 2007; Li et al., 2009) but none of these studies had tested on its efficacy as an assessment method to 
isolate good quality oocyte by fertilizing them. Therefore, the aim of the present study was to demonstrate the ability of annexin $\mathrm{V}$ assay as an alternative assessment of oocyte quality.

\section{Materials \& Methods}

\subsection{Materials}

Tissue culture media-199 with Earl's Salts (TCM-199), bovine serum albumin (BSA) EFAF, phosphate buffer saline (PBS), penicillin-streptomycin solution, Sodium pyruvate, Gentamycin sulphate, B-estradiol, fetal bovine serum (FBS), mineral oil, epidermal growth factor (EGF), follicle stimulating hormone (FSH), luteinizing hormone (LH), Annexin-V FITC, sodium chloride, potassium chloride, Magnesium chloride hexahydrate, sodium bicarbonate, calcium chloride dehydrate, Hypotaurine, D-Penicillamine, epinephrine, lactic acid (sodium salt), sodium metabisulphite, potassium dihydrogen fosfat, L-Glutamine, BME amino acid, MEM amino acid, Myo-Inositol and phenol red.

\subsection{Oocyte Collection}

All procedures have followed Institutional guideline. A total of 46 cattle's ovaries were collected at a local abattoir and placed in warm phosphate buffer saline (PBS) supplemented with $1 \%$ of antibiotic (10,000 IU penicillin and $10 \mathrm{mg}$ streptomycin). The ovaries were transported back to the laboratory within 3 hours after the animal was slaughtered. Oocytes recovery was done by slicing the ovaries on a petri dish containing $10 \mathrm{mg} / \mathrm{ml}$ of bovine serum albumin (BSA) dissolved in Dulbecco's phosphate buffered saline and $0.01 \%$ of penicillin and streptomycin mixtures. Later, morphologically healthy oocytes were selected using a dissecting microscope. Selection of the oocytes was based on these characteristics: 1) COCs with compact multilayer cumulus cells that are tightly adherent to the zona pellucida; 2) presence of homogenous appearing ooplasm with general appearance of transparent COCs. At completion. Once completed, a total of 239 healthy oocytes were obtained.

\subsection{Sperm Collection}

Bovine semen sample were collected through artificial vagina technique and cryopreserved. Briefly, the extended samples were chilled at $4^{\circ} \mathrm{C}$ for $3 \mathrm{hrs}$ prior to loading into $0.25 \mathrm{ml}$ French straw. Straw were then exposed to liquid nitrogen vapour for $9 \mathrm{~min}$ before plunging into liquid nitrogen for storage until required.

\subsection{Optimization of Staining Incubation Time}

A total of 83 COCs classified as morphologically healthy were washed twice in washing solution and twice in maturation (IVM) media. Lastly, these COC were then transferred into droplets containing IVM media, 1X binding buffer, $5 \mu \mathrm{L}$ Annexin V-FITC and $10 \mu \mathrm{L}$ PI. IVM droplets were prepared by mixing TCM 199 and 'heat stressed' serum at a ratio 9:1 and $1 \%$ of antibiotic. A total of $82 \mathrm{COC}$ were then incubated at $38^{\circ} \mathrm{C}$ for five minutes in $5 \% \mathrm{CO}_{2}$ humidified air. They were then observed under a fluorescent microscope at $5 \mathrm{~min}, 15 \mathrm{~min}$ and 24 hours intervals. Florescent results were visualized under a florescent microscope. Optimum incubation time was determined when florescent signal for Annexin V-FITC and PI was detectable using the naked eye of the microscope.

\subsection{In vitro Maturation (IVM)}

A total of 157 morphologically healthy COC was incubated for five minutes (optimized incubation time) with Annexin V FITC and PI. The COC were then grouped based on their fluorescent signals. Oocytes without any definitive fluorescent signal were sorted into the negative group-in which it is assumed as viable COC. While those with very prominent green and red fluorescent signals were grouped into the positive group. This group was classified as non-viable COC. Control group were COC with healthy morphology characteristic but non-stain. Oocytes in each group were later matured by transferring them into new IVM droplets prior to its incubation at $38^{\circ} \mathrm{C}$ in $5 \%$ humidified $\mathrm{CO}_{2}$ for $24 \mathrm{hrs}$. In all, control, positive and negative group was represented by 68,76 and 81 oocytes respectively.

\subsection{In vitro Fertilization (IVF)}

Frozen-thawed bull semen was mixed and centrifuged twice with sperm washing solution modified from Bracket and Olliphant (BO) media. The media was supplemented with heparin and antibiotic. Sperm suspension was then diluted in BO media supplemented with $2 \mathrm{mg} \mathrm{BSA} / \mathrm{ml}$ and $30 \mu \mathrm{L}$ calcium ionophore. Matured oocytes from both groups (positive and negative) were washed and partially denuded in oocyte washing solution prior to culture with sperm suspension at a final concentration of $1 \times 10^{6} \mathrm{spz} / \mathrm{ml}$. The mixed oocytes and sperm were then finally incubated at $38^{\circ} \mathrm{C}$ in $5 \% \mathrm{CO}_{2}$ for $18 \mathrm{hrs}$. 


\subsection{In vitro Culture (IVC)}

At $18 \mathrm{hrs}$ post-insemination (hpi), presumptive zygotes were mechanically denuded from the remaining cumulus cells and excessive sperm cells. Groups of 10 embryos were then placed in each $100 \mu \mathrm{L}$ droplets of CR1aa media supplemented with amino acid and FCS. The embryo cultures were then incubated at $38^{\circ} \mathrm{C}$ in $5 \% \mathrm{CO}_{2}$ for 3 days.

\section{Results}

Identification of negative and positive fluorescent signals is as shown in Figure 1. Figure 1(a) is an image of morphologically healthy oocytes under bright filed microscope. When the fluorescent light was on, Annexin V FITC had produce green florescent signal while PI a red florescent signal. General positive florescent signals are COC which express green and red signals (Figure 1(b)-A). Negative COC are cells that do not radiate any fluorescent signal (Figure 1(b)-B).
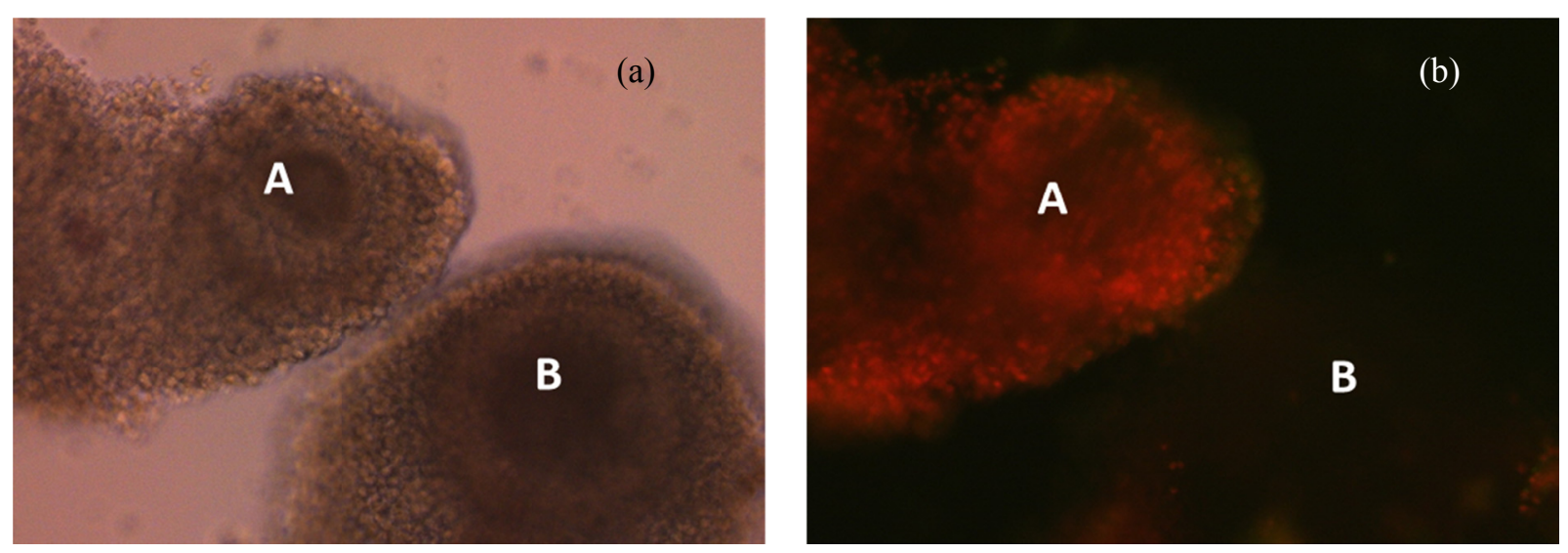

Figure 1. Cumulus oocytes complexes stained with Annexin V-FITC and PI. (a) is magification at X40 under bright field phase while (b) is fluorescent phase

A \& B: Relative position of each cell in relation to the images.

Table 1. Number and percentage of $\mathrm{COC}$ with positive and negative fluorescent signal according to their binding time

\begin{tabular}{lll}
\hline \multirow{2}{*}{ Binding time (min) } & \multicolumn{2}{l}{ No. Of COC with fluorescent signal (\%) } \\
\cline { 2 - 3 } & Positive & Negative \\
\hline 5 & $44(54)$ & $38(46)$ \\
15 & $48(56)$ & $36(44)$ \\
1440 & $-*$ & $-*$ \\
\hline
\end{tabular}

_* indicate no Annexin V- FITC and PI fluorescent signal.

The number of oocytes that had shown positive and negative fluorescent signals according to incubation time is presented in Table 1. Even though there was an increased number of COC that were positively tagged with Annexin V and PI over the time, but statistically the increase was insignificant. At 24 hrs no fluorescent signal was seen and was reported as such.

Table 2. Rate of cleavage of inseminated oocytes that negative and positive tagged with Annexin $\mathrm{V}$ and those morphologically healthy

\begin{tabular}{lll}
\hline Group & No. of oocyte & Cleavage rate (\%) \\
\hline Control & 68 & $45(66)$ \\
Positive & 76 & $38(50)^{*}$ \\
Negative & 81 & $64(79)^{*}$ \\
\hline
\end{tabular}

* indicates significant differences with $\left(\chi^{2}(2)=14.60, \mathrm{p}<0.05\right)$. 
Cleavage rate is a termed used to measure the percentage of inseminated oocytes which have cleaved to 2, 4 and up to 16 cells before progress to morula stage. Number of fertilized oocytes in control and experimental (positive and negative) groups that show cleavage on day-3 after fertilization is shown in Table 2. Statistical analysis had indicated that there was a significant difference $\left(\chi^{2}(2)=14.60, p<0.05\right)$ of cleavage rate between the three groups. A greater percentage of cleavage was observed among oocytes under negative $(79 \%)$ group followed by control $(66 \%)$ and positive $(50 \%)$ groups.

\section{Discussions}

One of the major cell physiological activities is to maintain an asymmetric distribution of its components between the inner and outer leaflets of the plasma membrane (Copenhagen, 2009). During apoptosis, phosphatidylserine (PS) is translocated from the inner to the outer leaflets. This exposure, function as a marker for macrophages to phagocyte the non-viable cells (Greenberg et al., 2006). In a fertility lab, identification of this exposed PS is facilitated by Annexin V labelled with fluoroisothiocyanate (FITC) which has been known to specifically bind to PS in the presence of calcium ion (Lang et al., 2003). When using Annexin V-FITC, PI is also used together as it is used to detect non-viable cells.

In early stages of apoptosis, membrane integrity of the oocyte remains unchanged. During this stage PS are already expressed on the oocyte cell wall. This is detected using Annexin V-FITC which is represented as a fluorescent green signal under the fluorescence microscope. As the oocyte reaches late stage apoptosis or necrosis, loss of membrane integrity would have occurred. This would enable PI to enter the cells. Presence of PI within the cells is represented as a red fluorescent signal under a fluorescence microscope (Figure 1(b)-A).

To date, various incubation duration and temperature are used to allow Annexin $\mathrm{V}$ to bind onto the non-viable oocytes. As an example, study by Li et al. $(2009)$ had incubated denuded goat's oocytes with Annexin V staining for $30 \mathrm{~min}$ at $4^{\circ} \mathrm{C}$ while Anguita et al. $(2009 ; 2007)$ had incubated bovine's oocytes for $15 \mathrm{~min}$ at $37-38^{\circ} \mathrm{C}$. Both afore mention methods had extremely long incubation periods as further development of oocyte were not their main priority. In this study, optimization of Annexin V staining binding time was done to minimize the exposure of COCs towards ambient temperature and also to avoid any delay in placing the cells to receive necessary nutrient for their development process. COC exposed to low temperature during recovery process have shown significant decrease in quantity and also quality of embryo produced (Matsushita, Tani, Kato, \& Tsunoda, 2004). Therefore the minimal binding time between the Annexin V and the translocated phosphatidylserine (PS) on the surface of non-viable cells is one of the crucial elements prior to its application as an assessor.

In this present study, development of oocytes was our main priority and so binding time were shorten as short as possible. Result indicated that suitable florescent signal from Annexin V-FITC can be obtained after a minimum incubation time of five minutes. In this period, Annexin V assay was able to bind with 44 non-viable oocytes. As these oocytes were initially classified as morphologically healthy, presence of the Annexin V-FITC had indicated that some morphologically healthy oocytes are biologically unhealthy. When binding time was increased to $15 \mathrm{~min}$, this assay had identified 48 non-viable cells. Increasing binding time to $24 \mathrm{hrs}$ had resulted in an absence of fluorescent signal. This may due to photobleaching, although further investigation is required to elucidate this mystery (Lavagnino, Zanacchi, \& Diaspro, 2011).

The efficacy of Annexin V assay in isolating the good quality (viable) oocytes from the non-viable oocytes are measured in the number of inseminated oocytes that had successfully cleave into 2 to 4 cells on day-3 of post-insemination. Results found that oocytes from the negative signal (viable oocytes) had a greater cleavage rate (79\%) followed by control group (morphologically healthy oocytes-66\%) and lastly positive group (non-viable oocyte - 50\%).

We would like to note that this study had its limitation. Staining used was an indirect assessment to the oocytes quality because the stain was only able to stain the surround cell (cumulus cells). The stain was unable to penetrate the thick cumulus layer and stain the oocyte. Identification cleaves cell stage to determine whether the zygotes were in a 2-cells stage of 4-cells stage was also not presented.

\section{Conclusion}

As a conclusion, oocytes that are morphologically healthy are actually composed of a mix of viable and non-viable oocytes. Therefore, this assay should be considered to be an alternative assessment in oocyte quality to improve in vitro fertilization simultaneously in enhancing the in vitro embryo production. But prior to this application, any toxic effect of the stains mentioned above towards the genetic development should also be investigated seriously. 


\section{Acknowledgement}

This research was supported financially by the Grant from AgroBiotechnology Institute (ABI) Malaysia (Grant No. 10-05-ABI-AB040), and Department of Physiology, Faculty of Medicine, National University of Malaysia (UKM). The authors would like to thank National Institute of Animal Biotechnology, Jerantut Malaysia and team from Sperm Science Group UKM for their assistance.

\section{References}

Anguita, B., Paramio, M. T., Morató, R., Romaguera, R., Jiménez-Macedo, A. R., Mogas, T., \& Izquierdo, D. (2009). Effect of the apoptosis rate observed in oocytes and cumulus cells on embryo development in $\begin{array}{llll}\text { prepubertal goats. Animal reproduction } & \text { science, }\end{array}$ http://dx.doi.org/10.1016/j.anireprosci.2009.01.007

Anguita, B., Vandaele, L., Mateusen, B., Maes, D., \& Van Soom, A. (2007). Developmental competence of bovine oocytes is not related to apoptosis incidence in oocytes, cumulus cells and blastocysts. Theriogenology, 67(3), 537-549. http://dx.doi.org/10.1016/j.theriogenology.2006.09.004

Bilodeau-Goeseels, S. (2001). Manganese inhibits spontaneous nuclear maturation in bovine cumulus-enclosed oocytes. Canadian Journal of Animal Science, 81(2), 223-228. http://dx.doi.org/10.4141/A00-074

Blondin, P., Bousquet, D., Twagiramungu, H., Barnes, F., \& Sirard, M. A. (2002). Manipulation of follicular development to produce developmentally competent bovine oocytes. Biology of reproduction, 66(1), 38-43. http://dx.doi.org/10.1095/biolreprod66.1.38

Camargo, L. S. A, Viana, J. H. M., Sá, WF, Ferreira, A. M., Ramos, A. A., \& Vale Filho, V. R. (2006). Factors influencing in vitro embryo production. Animal Reproduction, 3(1), 19-28.

Copenhagen, H. S. (2009). Themed issue: membrane biophysics. Soft Matter, 5, 3145-3147. http://dx.doi.org/10.1039/b912987c

De Wit, A. A, Wurth, Y. A., \& Kruip, T. A. (2000). Effect of ovarian phase and follicle quality on morphology and developmental capacity of the bovine cumulus-oocyte complex. Journal of animal science, 78(5), 1277-1283.

Greenberg, M. E., Sun, M., Zhang, R., Febbraio, M., Silverstein, R., \& Hazen, S. L. (2006). Oxidized phosphatidylserine-CD36 interactions play an essential role in macrophage-dependent phagocytosis of apoptotic cells. The Journal of Experimental Medicine, 203(12), 2613. http://dx.doi.org/10.1084/jem.20060370

Lang, K. S., Duranton, C., Poehlmann, H., Myssina, S., Bauer, C., Lang, F., ... Huber, S. M. (2003). Cation channels trigger apoptotic death of erythrocytes. Cell Death \& Differentiation, 10(2), 249-256. http://dx.doi.org/10.1038/sj.cdd.4401144

Lavagnino, Z., Zanacchi, F. C., \& Diaspro, A. (2011). Role of Scattering and Nonlinear Effects in the Illumination and the Photobleaching Distribution Profiles. Optical Fluorescence Microscopy, 75-84. http://dx.doi.org/10.1007/978-3-642-15175-0_4

Li, H. J., Liu, D. J., Cang, M., Wang, L. M., Jin, M. Z., Ma, Y. Z., \& Shorgan, B. (2009). Early apoptosis is associated with improved developmental potential in bovine oocytes. Animal reproduction science, 114(1), 89-98. http://dx.doi.org/10.1016/j.anireprosci.2008.09.018

Matsushita, S., Tani, T., Kato, Y., \& Tsunoda, Y. (2004). Effect of low-temperature bovine ovary storage on the maturation rate and developmental potential of follicular oocytes after in vitro fertilization, parthenogenetic activation, or somatic cell nucleus transfer. Animal reproduction science, 84(3), 293-301. http://dx.doi.org/10.1016/j.anireprosci.2004.02.008

Plourde, D., Vigneault, C., Lemay, A., Breton, L., Gagné, D., Laflamme, I., ... Robert, C. (2012). Contribution of oocyte source and culture conditions to phenotypic and transcriptomic variation in commercially produced bovine blastocysts. Theriogenology. http://dx.doi.org/10.1016/j.theriogenology.2012.01.027

van Engeland, M., Nieland, L. J. W., Ramaekers, F. C. S., Schutte, B., \& Reutelingsperger, C. P. M. (1998). Annexin $\mathrm{V}$-affinity assay: a review on an apoptosis detection system based on phosphatidylserine exposure. Cytometry, $31(1)$, http://dx.doi.org/10.1002/(SICI)1097-0320(19980101)31:1<1::AID-CYTO1>3.0.CO;2-R 